\title{
Estudos sobre a corrosão do latão em ambiente interno de um museu
}

Marcus Granato*, Leandro R. dos Santos ${ }^{* *}$ e Luiz R. M. de Miranda ${ }^{* *}$

\section{Resumo}

Os bens culturais são o produto e o testemunho das tradições e realizações intelectuais do passado e, dentre eles, as coleções de instrumentos científicos históricos constituem-se em testemunhos significativos da história da ciência. Neste trabalho, são apresentados resultados de estudos sobre a corrosão atmosférica do latão, um dos principais constituintes metálicos desses instrumentos, em seu próprio ambiente de guarda, um ambiente interno típico de um museu situado em região de clima tropical. Os estudos, com duração de 300 dias, utilizaram peças de latão, em composição similar àquela encontrada nas peças dos instrumentos, em testes preliminares, de exposição ao ambiente e em teste acelerado (imersão-emersão). Foi possível, em linhas gerais, simular de forma acelerada o processo real de corrosão atmosférica, através de testes de imersão-emersão adaptados, e os resultados obtidos por técnicas instrumentais de microscopia eletrônica de varredura (SEM) e difração de raios-X (DRX) mostraram que o primeiro produto de oxidação formado foi a cuprita, e que o processo mostrou-se muito lento. Não foi possível identificar compostos contendo enxofre, porém as análises por SEM mostraram a presença desse elemento na superfície das placas. Os resultados das análises por espectroscopia de retro-espalhamento Rutherford (RBS) e SEM permitem sugerir, a partir da medida de espessura das camadas de produtos de corrosão formadas, uma relação entre as escalas de tempo dos testes de imersão-emersão e de exposição atmosférica, resultando que cada 30 dias de ensaio acelerado corresponderam a cerca de 300 dias de exposição ao ambiente estudado.

Palavras-chave: Corrosão atmosférica. Latão. Conservação de metais.

\section{Studies into the corrosion of brass in an indoor museum environment}

\author{
Abstract \\ Cultural heritage is the product of and testament to past traditions and intellectual \\ achievements, of which collections of historic scientific instruments provide the most
}


significant of records in the history of science field. This work presents the results of studies into the atmospheric corrosion of brass, one of the main metal components of these instruments, in their own museum storage space, which is an indoor environment typical of a museum in a tropical clime. The studies, which lasted 300 days, were done on strips of brass with a similar composition to that of the instrument parts. They included preliminary tests, an environmental exposure test and an accelerated test (alternate immersion), which was adapted from the methodology proposed by M. Pourbaix. Overall, it was possible to simulate an acceleration of the real atmospheric corrosion process using adapted alternate immersion test. The results obtained by scanning electron microscopy (SEM) and x-ray diffraction (XRD) showed that the first oxidation product formed was cuprite, and that the process was very slow. It was not possible to identify any sulfur compounds, though the SEM analyses showed the presence of this element on the surface of the strips. The results of the Rutherford backscattering spectroscopy (RBS) and SEM analyses suggested that, based on the thickness of the layers of corrosion products formed, there was a relationship between the time scales of the alternate immersion and atmospheric exposure tests, whereby each 30 days of accelerated test corresponded to approximately 300 days of exposure to the environment under study.

Key-words: Atmospheric corrosion. Brass. Metals conservation.

\section{Corrosão e a conservação de instrumentos científicos}

A conservação e a restauração são temáticas de grande interesse para os profissionais de museus, e é justamente durante a restauração que um objeto corre o maior risco de dano e pode determinar a perda ou ganho de um patrimônio que, em última análise, é de toda a sociedade. As decisões que estão envolvidas nesses processos são igualmente importantes seja o objeto em questão uma tela de pintura à óleo, uma caixa de marfim, ou um microscópio ou telégrafo. Em geral, a conservação e a restauração estão envolvidas com uma luta continuada contra os agentes ambientais, que têm o efeito de acelerar a deterioração dos materiais constituintes desses objetos. 
Instrumentos científicos, essenciais para a astronomia, a medicina, a meteorologia, a matemática, a física e outras ciências, são fabricados utilizando-se técnicas complexas e uma grande variedade de materiais, que exigem cuidados específicos de conservação. Basicamente feitos de metais, os instrumentos científicos de valor histórico (feitos nos séculos 18 e 19) estão sujeitos à corrosão e a outros processos associados aos metais. Cobre, latão e bronze são os metais mais comuns encontrados nesses objetos, substituindo, na maioria das vezes, o que antes era de madeira. O latão laminado foi utilizado para a fabricação de tubos de lunetas, telescópios e acessórios de sextantes e teodolitos, enquanto o aço, ou mesmo o latão, era muito utilizado para produção de parafusos e porcas. O alumínio começou a ser utilizado apenas no início do século 20 , mesmo assim somente em pequenas peças. A prata e suas ligas eram utilizadas para a fabricação de escalas em sextantes, por exemplo, pois sua característica de ser mais macia permitia gravar as marcações e divisões de forma mais precisa (MINIATI; BRENNI, 1993).

De forma a desenvolver estudos que permitissem a conservação e a restauração de instrumentos científicos em museus de Ciência e Técnica (C\&T), verificou-se a necessidade de coletar informações sobre o processo de corrosão do latão, principal componente dos instrumentos científicos existentes em coleções museológicas. Poucos são os estudos sobre corrosão em ambientes fechados realizados com cobre e suas ligas. Aqueles encontrados na literatura (RICE et al, 1980; SCHUBERT; D'EGIDIO, 1990) utilizavam apenas o cobre e sempre apontaram o processo como muito mais lento (cerca de 100 vezes) do que o de corrosão em áreas externas, ressaltando a não formação de pátinas na superfície do metal. No entanto, em todos os casos, um fato aparentava ser responsável pelos resultados obtidos: a umidade relativa dos ambientes era baixa (<65\%, SCHUBERT; D'EGIDIO, 1990); ou muito baixa (<26\%, RICE et al, 1980).

Em vista desse panorama, verificou-se a necessidade de realizar estudos sobre a corrosão do latão no próprio ambiente de guarda dos objetos de um museu, avaliando, assim, in loco o processo de degradação a que esses objetos estariam submetidos. O museu escolhido para a realização dos estudos foi o Museu de Astronomia e Ciências Afins (MAST - www.mast.br), situado em região de clima 
tropical (Rio de Janeiro) e sem sistemas de controle do ambiente em sua área de guarda de objetos.

O MAST, que foi aberto ao público em 1985, é um instituto de pesquisa do Ministério da Ciência e da Tecnologia. Uma de suas principais atividades é a preservação de sua coleção de instrumentos científicos, hoje com cerca de 2.000 objetos. Uma parte desses instrumentos é proveniente do Observatório Nacional e foi utilizada em serviços e pesquisas importantes para o país, como a marcação da hora oficial do Brasil, a previsão do tempo e de fenômenos astronômicos, a delimitação de fronteiras e o mapeamento magnético do solo. A maioria desse grupo de instrumentos foi fabricada nos séculos 19 e início do 20, mas alguns dos instrumentos mais interessantes da coleção, como o quadrante de J. Sisson e o teodolito de G. Adams, datam do século 18.

\section{Procedimentos experimentais}

Os ensaios, de três tipos, foram denominados de preliminares, de exposição atmosférica e de imersão-emersão, tendo sido realizados dentro de uma vitrine instalada numa das salas da área de guarda de coleções do MAST. A reserva técnica do MAST é do tipo visitável e, durante os estudos, manteve-se a sala onde se realizaram os experimentos aberta à visitação pública, viabilizando uma maior representatividade da composição atmosférica desse ambiente. Os materiais utilizados na construção da vitrine (compensado de madeira e acrílico) foram os mesmos empregados em vitrines instaladas em outras salas da reserva técnica do MAST. Trabalhos recentes (HATCHFIELD, 2002) apresentam como orientação a utilização desses materiais em museus, sendo considerados os menos prejudiciais à conservação, principalmente para objetos metálicos.

Uma placa de latão com espessura de $1 \mathrm{~mm}$ e composição química similar àquela dos instrumentos científicos do museu foi adquirida. A composição da liga das amostras foi definida com base nos resultados obtidos nas análises de microscopia eletrônica de varredura, pela técnica de espectrometria de energia de dispersão (EDS), realizadas em partes constituintes das peças de instrumento científico histórico pertencente ao acervo do MAST (GRANATO; SANTOS; MIRANDA, 2002). Amostras foram então cortadas em guilhotina, nas dimensões $3,0 \times 3,0 \mathrm{~cm}$. Para os 
testes preliminares, tais amostras foram previamente preparadas da seguinte forma: lixadas com carbeto de silício até a lixa de granulometria 600, polidas com alumina, rinsadas com acetona e desengorduradas com tricloroetileno em equipamento de ultra-som (2 min). Para os testes sistemáticos, foram jateadas com microesferas de vidro, rinsadas com acetona e desengorduradas com tricloroetileno em equipamento de ultra-som (2 min). Um lote de 40 amostras foi cortado nas dimensões $1,0 \times 1,0 \mathrm{~cm}$, de forma a poderem ser utilizadas para análise pela técnica de espectrometria de retro-espalhamento Rutherford (RBS), utilizando o mesmo procedimento de preparação de superfícies para as amostras dos testes preliminares.

Para avaliação da estrutura do latão adquirido, amostras foram polidas com lixa na série usual até granulometria 600 , seguindo-se o polimento com pasta de diamante nas granulometrias $3 \mu \mathrm{m}$ e $1 \mu \mathrm{m}$. Com a superfície polida, seguiu-se o ataque químico com um reagente adequado, utilizando-se uma solução de cloreto férrico e ácido clorídrico $\left(1 \mathrm{~g} \mathrm{FeCl}_{3}, 10 \mathrm{ml}\right.$ de $\mathrm{HCl}, 100 \mathrm{ml}$ de água destilada), à temperatura ambiente e com um tempo de contato de 1 minuto (VANDER VOORT, 1984). A amostra foi então observada em microscópio ótico e fotografada para registro.

Nos testes preliminares, as amostras de latão foram colocadas na reserva técnica do MAST, em posição horizontal, para avaliação da influência das partículas de poeira sobre o processo corrosivo. Ao longo de três meses, foram retiradas amostras a intervalos de 10 dias, para análise por microscópio eletrônico de varredura (marca LEO, modelo S440), utilizando tanto imagens obtidas por elétrons secundários (SEI), que destacam a topografia da superfície e a eventual presença de partículas agregadas, como imagens obtidas por elétrons retroespalhados (BSD), que privilegiam o contraste entre regiões ou fases com diferentes composições químicas.

Nos demais ensaios, o acompanhamento do processo foi realizado através da observação visual e análise das amostras, retiradas a intervalos variados de tempo (10, 30, 60, 90, 150, 300 dias), por microscopia eletrônica de varredura (SEM), espectrometria de difração de raios-X (DRX) e espectrometria de retroespalhamento Rutherford (RBS). Desta vez, a observação no microscópio eletrônico de varredura incluiu, além dos dois tipos de imagem já mencionados, a análise química pontual por EDS, por meio de um sistema Link ISIS acoplado ao microscópio. As análises 
por DRX utilizaram um difratômetro Bruker-AXS modelo D5005. Os espectros de difração obtidos foram interpretados por comparação com padrões contidos na base de dados do ICDD - International Centre for Diffraction Data - de 1996.

Para os testes de exposição atmosférica, foi fixada à parede, dentro da vitrine citada anteriormente, uma estante em compensado de madeira nas dimensões $82 \times 45 \times 3 \mathrm{~cm}$. A estante apresentava 12 prateleiras onde foram posicionadas as amostras em ângulo de 45 graus com a horizontal.

Os ensaios de imersão-emersão foram realizados utilizando uma adaptação da metodologia estipulada por Pourbaix (1987). Esta consiste, em linhas gerais, na imersão dos corpos de prova a determinados meios corrosivos que simulam atmosferas específicas, em períodos alternados com períodos de secagem por exposição ao ar.

No estudo realizado, devido à necessidade de reprodução do ambiente onde se encontram depositadas as peças pertencentes ao acervo do MAST, foi projetada e montada no Laboratório de Corrosão da Coppe/UFRJ (Labcorr) uma unidade portátil de ensaios de imersão-emersão e instalada no interior da vitrine já mencionada. $A$ Figura 1 apresenta um desenho esquemático da unidade de imersão-ermersão.

Foram utilizados 6 corpos de prova presos a hastes de cobre e isoladas com resina epoxi, de forma a permitir a realização de medidas do potencial eletroquímico. Tais medidas foram efetuadas empregando-se um eletrodo de referência de sulfato de potássio saturado e um multímetro digital marca Minipa ET- 2092. Visando evitar maiores contaminações da solução pelo sulfato do eletrodo, durante as medidas de potencial, foram utilizados recipientes ligados às cubas através de pontes salinas contendo a mesma solução das cubas.

De forma a simular, da melhor forma possível, a atmosfera da área interna da reserva técnica do MAST, a solução utilizada nas cubas foi água bidestilada e deionizada, após aclimatação no local de ensaio por período mínimo de 1 semana. A solução utilizada apresentava pH 5,0, potencial de oxi-redução (Eh) de $+360 \mathrm{mV}$ e resistividade de $314 \mathrm{k} \Omega$. Duas cubas sobressalentes, com a mesma solução, foram 
mantidas no local, de forma a permitir o nivelamento da cuba de trabalho. As lâmpadas foram mantidas apagadas, visto que não há exposição ao sol em ambientes fechados.
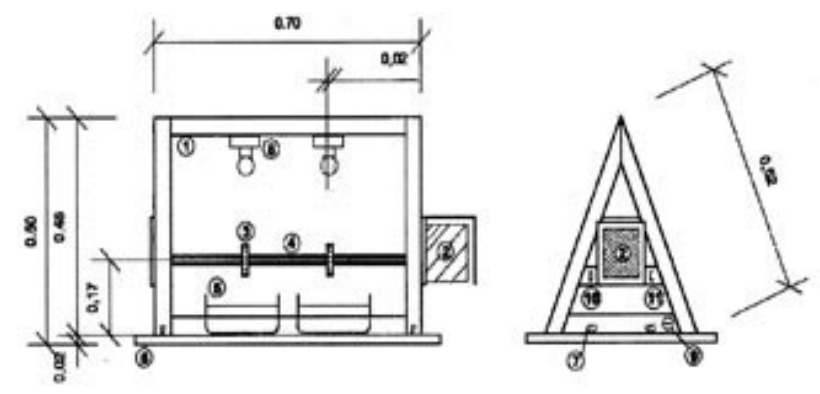

SCALE 1:10
UNITS IN METERS

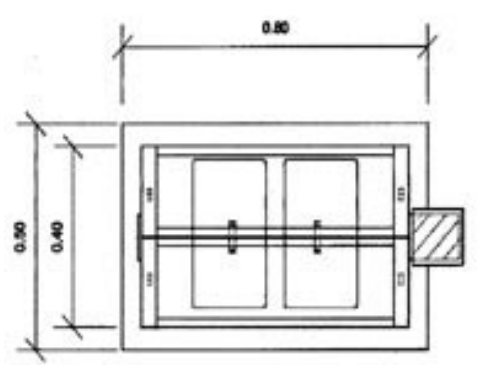

1 - ALUMNUM STRUCTURE

2-MOTOR

-DISCS FOR SAMPLES FDXATION $\sigma=0.07$

4-ROTATIONAL AXIS

- PLASTIC BOXES

- WOODEN BASIS

7 - SCREWS

8 - LAMPS

9-PLUG

11 - LAMP SWITCH

FIGURA 1 - Diagrama esquemático da unidade de laboratório para testes de imersão-emersão. Desenho: Ivo A. Almico e Marcus Granato.

Ao final do estudo (300 dias de ensaio), as amostras de latão foram secionadas, embutidas em resina, polidas e observadas em SEM para avaliação da espessura das camadas de produtos de corrosão formadas.

As análises por RBS foram gentilmente realizadas pelo Laboratório Van de Graaff do Departamento de Física da Pontifícia Universidade Católica do Rio de Janeiro (PUCRJ). O objetivo dessas análises foi determinar a espessura das camadas de produtos de oxidação formadas nas amostras. Todas as demais análises (via úmida e instrumental) citadas neste estudo foram gentilmente realizadas pela Coordenação de Análises Minerais do Centro de Tecnologia Mineral (Cetem-MCT).

\section{Resultados e discussão}

\subsection{Estudos preliminares}

A composição química das amostras de latão utilizadas pode ser observada a seguir: $67,24 \%$ cobre (p/p), 32,74\% zinco (p/p), 0,01\% estanho (p/p), 0,01\% chumbo (p/p). Além da composição, foi determinada a sua estrutura, a partir da utilização de 
técnicas metalográficas e observação em microscópio ótico. Os resultados podem ser observados na Figura 2, a liga trata-se de um latão $\alpha$.

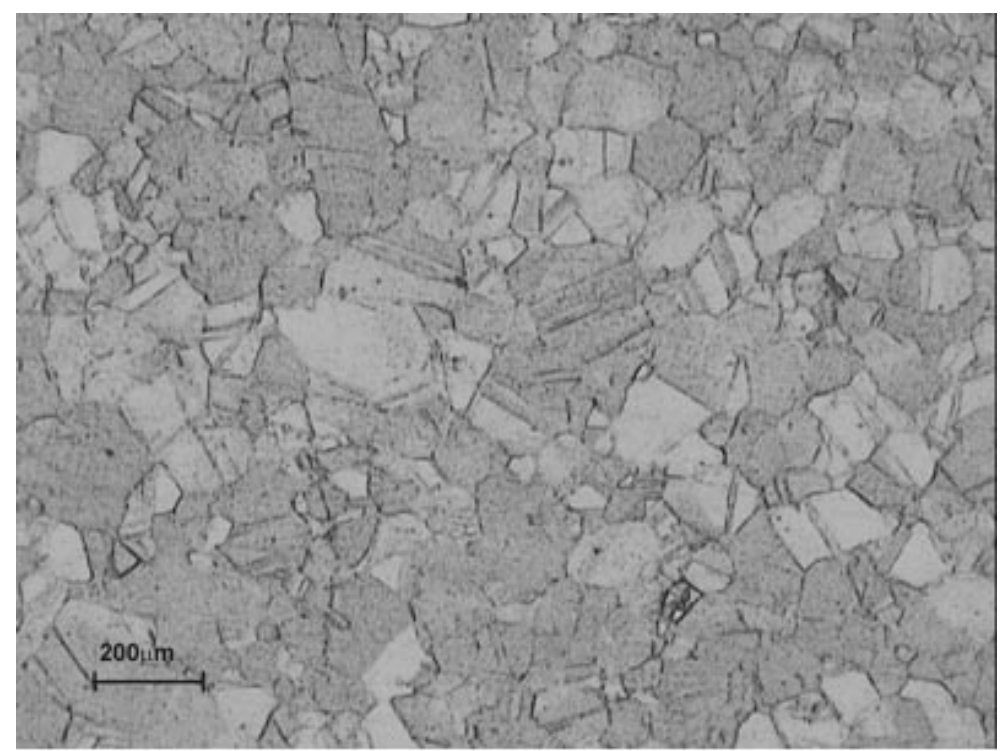

FIGURA 2 - Imagem resultante de análise metalográfica realizada na amostra de latão (aumento de 200x). Fotografias: Coordenação de Análises Minerais do Centro de Tecnologia Mineral.

As imagens apresentadas na Figura $3(\mathrm{a}, \mathrm{b})$, produzidas por SEM, apresentam alguns resultados relativos a esse período preliminar de estudos.

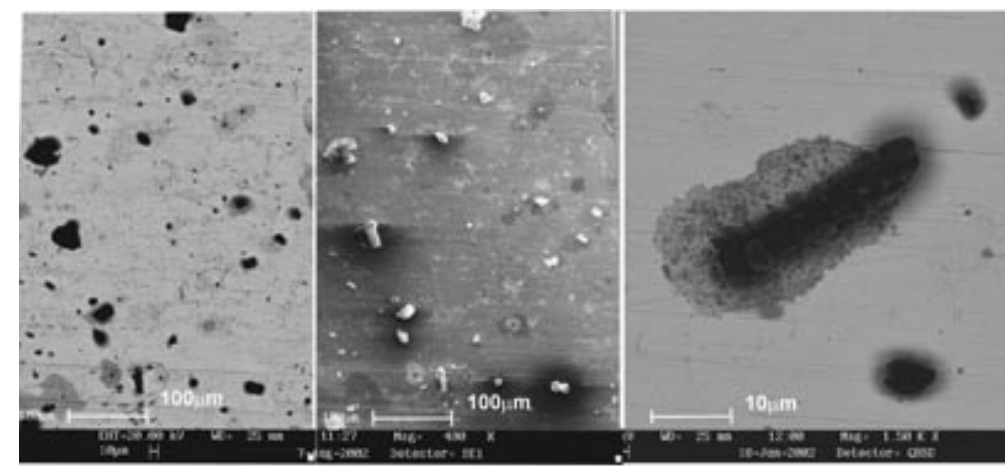

FIGURA 3 ( $a$, $b$ and $c)$ - Imagens obtidas por SEM de amostras com indicios de corrosão correlacionados com a presença de particulas de poeira. Em a e b-imagens da superficie produzida com aumento de $400 x$ (BSD e SEI respectivamente). Em c - Imagem da superfície com 4000x de aumento (BSD), apresentando partícula de poeira e área alterada por corrosão. Fotografias: Coordenação de Análises Minerais do Centro de Tecnologia Mineral.

As imagens em a apresentam a superfície do latão coberta por várias partículas de poeira, que aparecem em escuro na imagem do lado esquerdo (BSD), por serem compostas de elementos mais leves que os metais da liga e aparecem bem definidas como corpos estranhos sobre a superfície do metal na imagem à direita $b$ (SEI), onde se observa a morfologia das partículas pousadas sobre a superfície. 
A imagem c, obtida por SEM pela técnica BSD, apresenta um exemplo típico de partícula de poeira (em cor bem escura), originando o processo corrosivo na superfície metálica. A área em torno da partícula apresenta produtos de oxidação, acompanhando o formato da partícula de poeira que foi determinante para o início do processo corrosivo.

O processo observado parece ser típico da corrosão por aeração diferencial. Quando da ancoragem de uma partícula de poeira sobre a superfície metálica, criase uma região de aeração diferencial, propiciando uma diferença de potencial que ocasiona a geração de uma "pilha", onde a superfície coberta pela partícula funciona como anodo e o restante da superfície metálica como catodo.

Como é bem conhecido, o processo de aeração diferencial promove uma acentuada dissolução nas regiões pouco aeradas (regiões anódicas), e de não corrosão nas regiões bem aeradas (regiões catódicas). Tal processo pode promover, localizadamente, danos de grande monta na superfície metálica. O processo tem comportamentos diferentes de acordo com o pH da solução circundante. No caso, como o pH está sempre abaixo de 7 (área urbano-industrial, com presença de gases geradores de ácidos), o resultado é que a aeração diferencial provocará um aumento de velocidade de corrosão das zonas não aeradas (POURBAIX, 1973).

Nazaroff et al (1993) publicaram um texto bastante completo sobre a presença de partículas sólidas em ambientes de museus, incluindo a medição da concentração em diversos locais (internos e externos) e a análise de diversas alternativas para reduzir o problema nesses espaços. No entanto, os autores não discutem ou explicam como ocorre o processo que provoca danos às peças metálicas pela interação com as partículas de poeira. Os resultados aqui obtidos parecem esclarecer como e por que ocorre esse processo.

A presença de partículas de poeira pode ser determinante para iniciar o processo de corrosão atmosférica em ambientes de museus; sua presença deve ser, portanto, evitada sempre que possível. 


\subsection{Estudos sistemáticos}

A Figura 4 ( $a, b$ e c) mostra imagens da superfície das amostras, obtidas por microscopia eletrônica de varredura (BSD), no momento inicial dos testes, mostrando informações referentes ao seu aspecto e à composição química elementar.

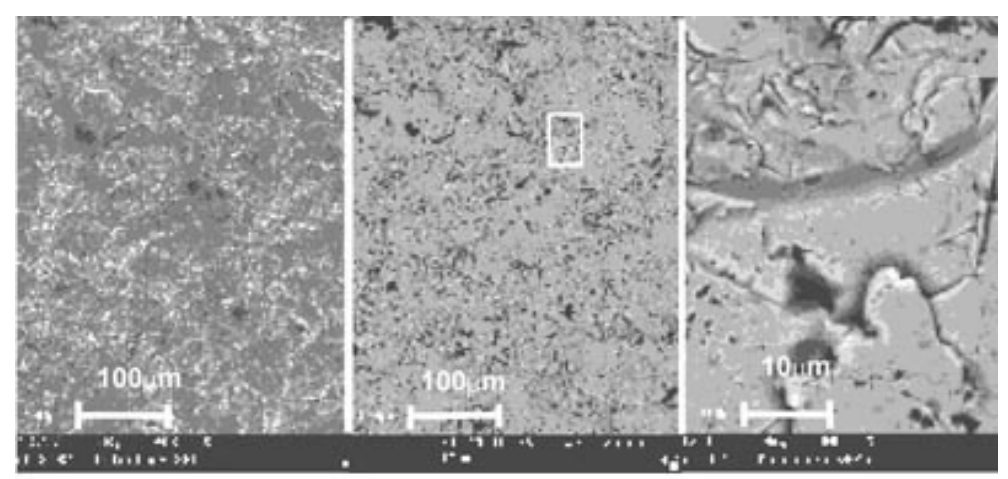

FIGURA 4 ( $a$, b and $c$ ) - Imagens obtidas por SEM, em dois aumentos ( 400 e 4000x), pela técnica de BSD (a) e SEI (b), mostrando a superfície da placa de latão antes de ser submetida aos testes de corrosão. Fotografias: Coordenação de Análises Minerais do Centro de Tecnologia Mineral.

A imagem em a mostra a superfície com grande área específica, devido ao tratamento de jateamento ao qual foi submetida, o que aumenta a área de contato com o ambiente, possibilitando uma aceleração das reações típicas dos processos corrosivos. Na imagem apresentada ao centro (b), com ampliação de 400x, foi selecionada uma área que foi ampliada mais 10 vezes, gerando um aumento final de $4.000 \mathrm{x}$, resultando na imagem apresentada à direita (c). Nela os pontos mais escuros, quase pretos, são resquícios do material utilizado como meio abrasivo no jateamento (micro-esferas de vidro) ou buracos produzidos no tratamento da superfície. A liga de cobre-zinco aparece em cinza, constituindo a totalidade do que está apresentado nessa cor.

\subsubsection{Ensaio de imersão-emersão}

A Figura 5 mostra a variação do potencial eletroquímico das amostras de latão com o tempo, durante os 300 dias de ensaio.

Verifica-se, pelo gráfico, uma elevação brusca do potencial desde $270 \mathrm{mV}$ até $410 \mathrm{mV}$ no início do ensaio, seguido de uma variação dos valores em torno de $300 \mathrm{mV}$, estabilizando-se em torno de $280 \mathrm{mV}$, por volta do centésimo dia de ensaio. Estas variações de potencial podem estar relacionadas com o não recobrimento total da 
superfície da amostra por produtos de oxidação; o total recobrimento foi verificado aos 150 dias de estudo. Com 120 dias de ensaio, um problema operacional determinou a troca do eletrólito do sistema. Tal fato provocou a elevação do potencial de eletrodo a patamares $(380 \mathrm{mV})$ próximos ao nível de pico verificado no início do ensaio $(400 \mathrm{mV})$, estabilizando-se, com o decorrer do tempo, em torno de $310 \mathrm{mV}$. Isso demonstra que a variação da composição do eletrólito interfere diretamente no sistema, não sendo suficiente, no entanto, para desestabilizá-lo.

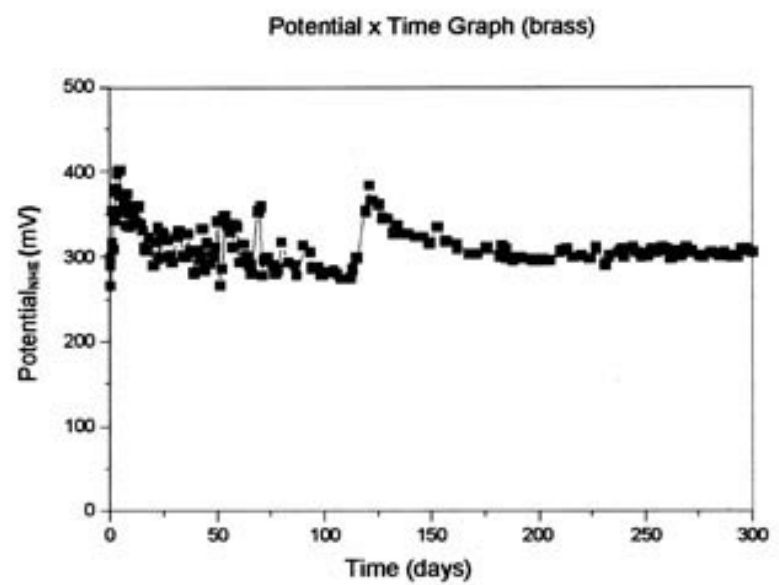

FIGURA 5 - Gráfico relacionando o potencial médio de eletrodo das amostras de latão com o tempo de ensaio de imersão/emersão. Desenho: Marcus Granato.

$\mathrm{O} \mathrm{pH}$ da solução foi medido periodicamente, após a estabilização do potencial, sendo sempre em torno de 5,0. As condições de $\mathrm{pH}$ e Eh, observadas no período de estabilidade, mostram, pela consulta ao diagrama de Pourbaix (Eh $\times \mathrm{pH}$ ) para o sistema cobre-água (POURBAIX, 1973), que a espécie termodinamicamente estável é a cuprita.

A seguir, serão apresentados e avaliados os resultados analíticos obtidos relativos às amostras retiradas com 10, 30, 60, 90, 150 e 300 dias de operação.

As análises por DRX produzidas até os 90 dias apresentaram sempre o mesmo resultado (GRANATO, 2003), onde foi identificada apenas a fase cúbica de face centrada majoritária da liga. Aos 150 dias detectou-se a presença do óxido de cobre denominado cuprita $\left(\mathrm{Cu}_{2} \mathrm{O}\right)$, além da liga propriamente dita. Aos 300 dias, observouse o mesmo resultado (GRANATO, 2003). A Figura 6 apresenta o resultado da 
análise para 150 dias, foi utilizada a radiação cobre K- $\alpha$. O Quadro 1 a seguir mostra os ângulos para os picos observados e as fases relacionadas.

Quadro 1 - Detalhamento dos resultados de DRX, ângulos para os picos observados e as fases relacionadas.

\begin{tabular}{|l|l|l|}
\hline Ângulo aproximado & Fase & Valor tabelado (composto puro) \\
\hline 29,5 & $\mathrm{Cu}_{2} \mathrm{O}$ & 29,69 \\
\hline 36,5 & $\mathrm{Cu}_{2} \mathrm{O}$ & 32,38 \\
\hline 42,2 (superposição de picos) & $\mathrm{Cu}_{2} \mathrm{O}$ & 42,21 \\
& $\mathrm{Cu}$ CFC & 43,295 (Cu puro) \\
\hline 49,0 & $\mathrm{Cu}$ CFC & 50,431 (Cu puro) \\
\hline 61,5 & $\mathrm{Cu}_{2} \mathrm{O}$ & 61,23 \\
\hline
\end{tabular}

Macroscopicamente, a superfície das amostras tornou-se opaca a partir do segundo dia de ensaio; aos sessenta dias estava coberta por uma camada de coloração marrom escura, típica dos óxidos de cobre; aos 150 dias mostrou-se esverdeada, em tom bem escuro, mantendo-se assim até o final do teste. Essa última coloração é típica dos compostos carbonatados como a malaquita $\left(\mathrm{CuCO}_{3} \cdot \mathrm{Cu}(\mathrm{OH})_{2}\right)$ e a azurita $\left(2 \mathrm{CuCO}_{3} . \mathrm{Cu}(\mathrm{OH})_{2}\right)$, ou sulfatados de cobre como a brocantita $\left(\mathrm{CuSO}_{4} \cdot 3 \mathrm{Cu}(\mathrm{OH})_{2}\right)$ e a antlerita $\left(\mathrm{CuSO}_{4} \cdot 2 \mathrm{Cu}(\mathrm{OH})_{2}\right)$. A presença desses compostos será função do $\mathrm{pH}$ e do Eh do sistema, como bem demonstrado por Lago (2001).

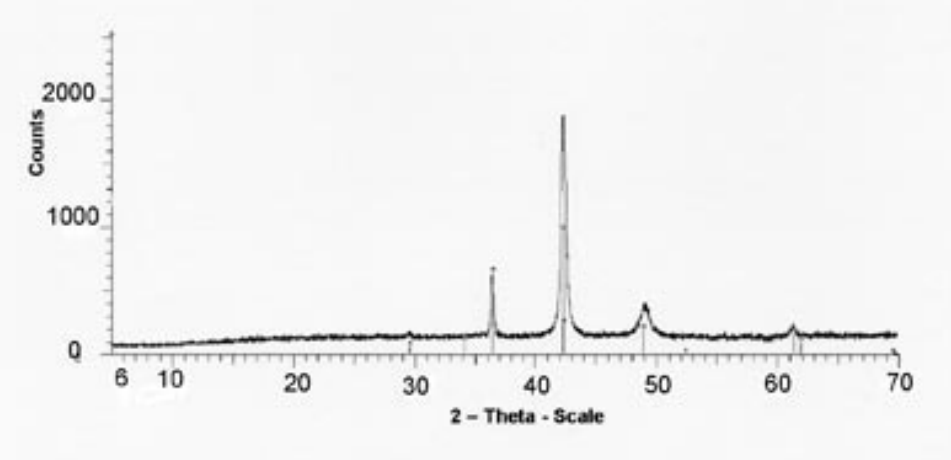

FIGURA 6 - Gráfico produzido pela análise por difração de raios-X da amostra retirada do teste de imersão-emersão aos 150 dias de ensaio. Desenho: Coordenação de Análises Minerais do Centro de Tecnologia Mineral.

Aos 10 dias de ensaio foram identificadas por SEM (técnica BSD) pequenas áreas de alteração, provenientes de processos de oxidação. No entanto, somente com a ampliação de $4.000 x$ foi possível identificá-las, caracterizando que o processo 
estava realmente em seu início e as áreas de alteração se apresentavam com dimensões muito reduzidas, menores que $1 \mu \mathrm{m}$ (GRANATO, 2003).

Após 30 dias de ensaio, já foi possível visualizar na imagem obtida por SEM (técnica BSD) ampliada em 400x algumas áreas que apresentavam alterações provenientes de processos de oxidação. Estas áreas apresentavam formatos arredondados, de dimensões na faixa dos $10 \mu \mathrm{m}$, e alongados, com comprimento alcançando valores de até $120 \mu \mathrm{m}$ (GRANATO, 2003). A análise por SEM (técnica EDS) permitiu verificar a presença, nas áreas com produtos de oxidação, dos metais formadores da liga (Cu e $\mathrm{Zn}$ ) e do elemento oxigênio, sugerindo a presença de um produto de corrosão contendo os metais e oxigênio, provavelmente um óxido (cuprita) (GRANATO, 2003).

Nesse período, os produtos de oxidação ainda se encontravam de forma espaçada e não se observou, ao microscópio, a formação de uma camada contínua na superfície da amostra. Os mesmos resultados foram verificados nas amostras de 60 e de 90 dias de teste, a menos das formas alongadas observadas anteriormente, terem evoluído para crescimentos que pareciam acompanhar os contornos de grão da microestrutura da liga. A Figura 7 mostra imagens obtidas por SEM (técnica BSD) dessas áreas espalhadas pela superfície, obtidas aos 90 dias, em aumentos de 400 e 4.000 vezes. A comparação da imagem à esquerda, na Figura 7 com a Figura 2 permite verificar que os grãos da microestrutura da liga original possuem formato semelhante ao aqui observado, permitindo supor a ocorrência de um processo de oxidação preferencial nos contornos dos grãos da estrutura.

Segundo Stambolov (1985), a corrosão de latões que apresentam apenas uma fase $\alpha$ se inicia e ocorre preferencialmente nos contornos de grão enriquecidos em zinco. Posteriormente, o processo corrosivo atinge a fase $\alpha$. Parece ser esse o caso aqui observado, pois a liga de cobre-zinco utilizada nos ensaios apresentava apenas uma fase.

A análise por SEM (técnica EDS) das áreas alteradas permitiu verificar a presença de enxofre, além da presença dos elementos apresentados anteriormente $(\mathrm{Cu}, \mathrm{Zn}$ e O), indicando a possível formação na superfície de um novo composto contendo os 
metais, oxigênio e enxofre (GRANATO, 2003). A presença de enxofre não havia sido identificada anteriormente, indicando uma possível evolução na formação dos produtos de oxidação, em mecanismo já constatado por Pourbaix (1973).

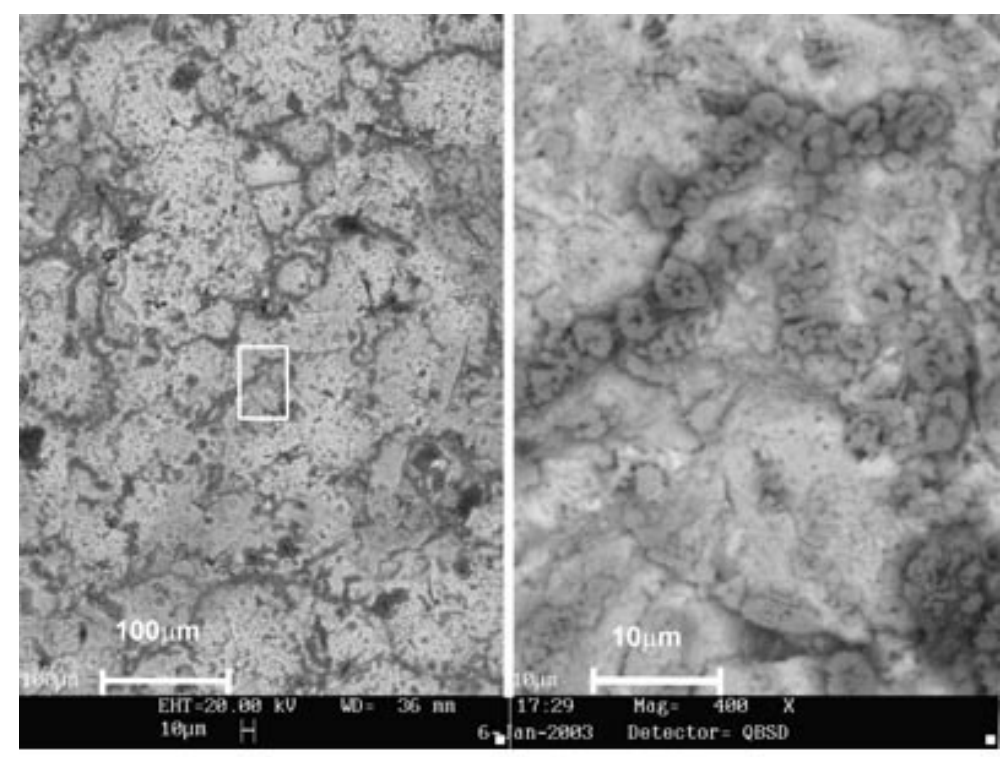

FIGURA 7 - Imagens obtidas por SEM, em dois aumentos ( 400 e $4000 x$, técnica de BSD - composição), mostrando a superficie da placa de latão após 90 dias de ensaio acelerado. Fotografias: Coordenação de Análises Minerais do Centro de Tecnologia Mineral.

Após 150 dias de ensaio, observou-se a formação de camadas continuadas de produtos de oxidação na superfície das amostras, sempre com o mesmo comportamento já verificado.

Os resultados obtidos após 300 dias de teste mostram a formação de uma camada espessa de produtos de oxidação em toda a superfície da placa. A Figura 8, mostra imagens típicas obtidas por SEM (BSD-composição) das áreas de alteração espalhadas pela superfície em aumentos de 400 e 4.000 vezes.

Verifica-se, na imagem mais ampliada, a formação de rachaduras na camada de produtos de oxidação em função da eliminação brusca da umidade da camada espessa formada, pela ação do vácuo da câmara do SEM. Confirma-se a existência de um comportamento do processo, mesmo em sua evolução, em acompanhar as formas dos contornos de grão da liga, mesmo com um depósito relativamente mais espesso formado. Análises realizadas por EDS nas áreas escuras e claras indicaram a presença dos metais ( $\mathrm{Cu}$ e $\mathrm{Zn}$ ) formadores da liga e de oxigênio e enxofre, aparentemente em composição diferenciada (GRANATO, 2003). 


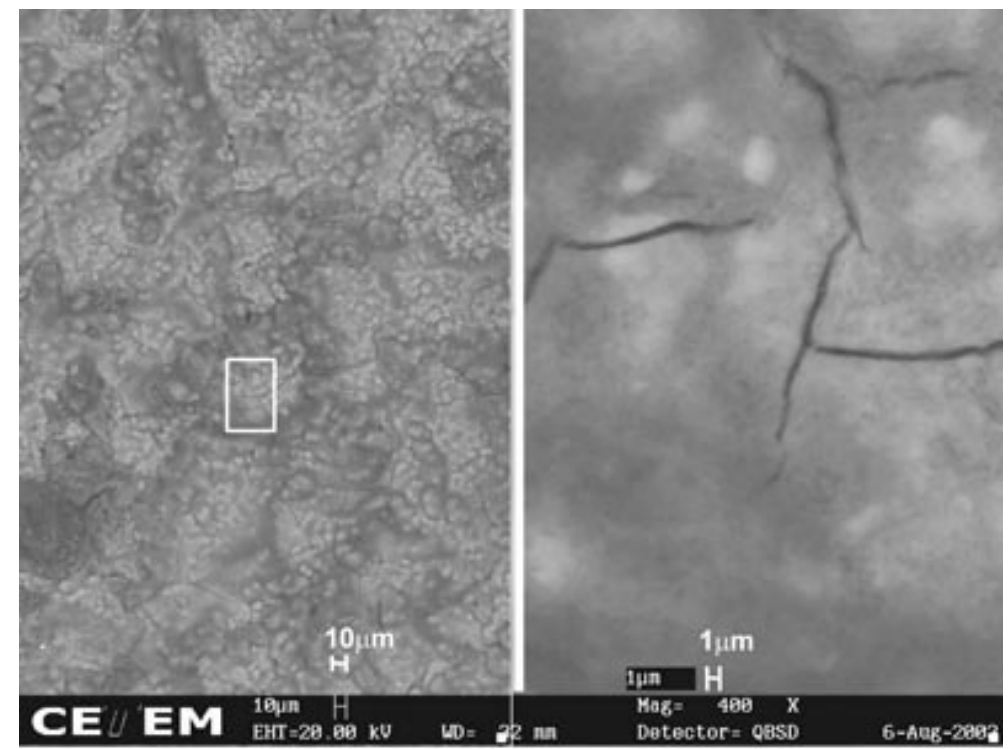

FIGURA 8 - Imagens obtidas por SEM, em dois aumentos ( 400 e $4000 x$, técnica de BSD), mostrando a superficie da placa de latão com 300 dias de ensaio acelerado.

Fotografias: Coordenação de Análises Minerais do Centro de Tecnologia Mineral.

Os resultados obtidos pela análise por RBS serão apresentados em gráficos comparando a amostra original com aquela referente a um determinado período de ensaio. A Figura 9 (a, b, c e d), mostra os gráficos obtidos para as amostras coletadas com 30, 90, 150 e 300 dias. A análise da amostra coletada com 60 dias enfrentou problemas operacionais produzindo resultados não confiáveis. As setas nas figuras indicam a posição de cada elemento, caso este estivesse na superfície da amostra.

$\mathrm{Na}$ amostra original, antes dos ensaios, verifica-se, além da presença dos elementos de liga $(\mathrm{Cu}$ e $\mathrm{Zn})$ o silício, provavelmente proveniente do material utilizado no preparo da superfície (abrasivo). Esse último elemento (Si) não é detectado nos resultados obtidos com as amostras provenientes dos ensaios, não sendo constitutivo das camadas de produtos de corrosão formadas.

A comparação entre os gráficos mostra o aumento do degrau entre as curvas referentes à amostra original e à amostra coletada com o tempo de ensaio, indicando o crescimento da camada de produtos de oxidação na superfície do latão. A espessura da camada pode ser quantificada por essa técnica de análise, nas amostras coletadas com 30 e 90 dias, valendo respectivamente $0,05 \mu \mathrm{m}$ e $0,8 \mu \mathrm{m}$. Nas amostras subseqüentes, tal procedimento não foi possível, pois a camada 
formada era mais espessa que o limite superior de medição do método (aqui, de $1,5 \mu \mathrm{m})$.

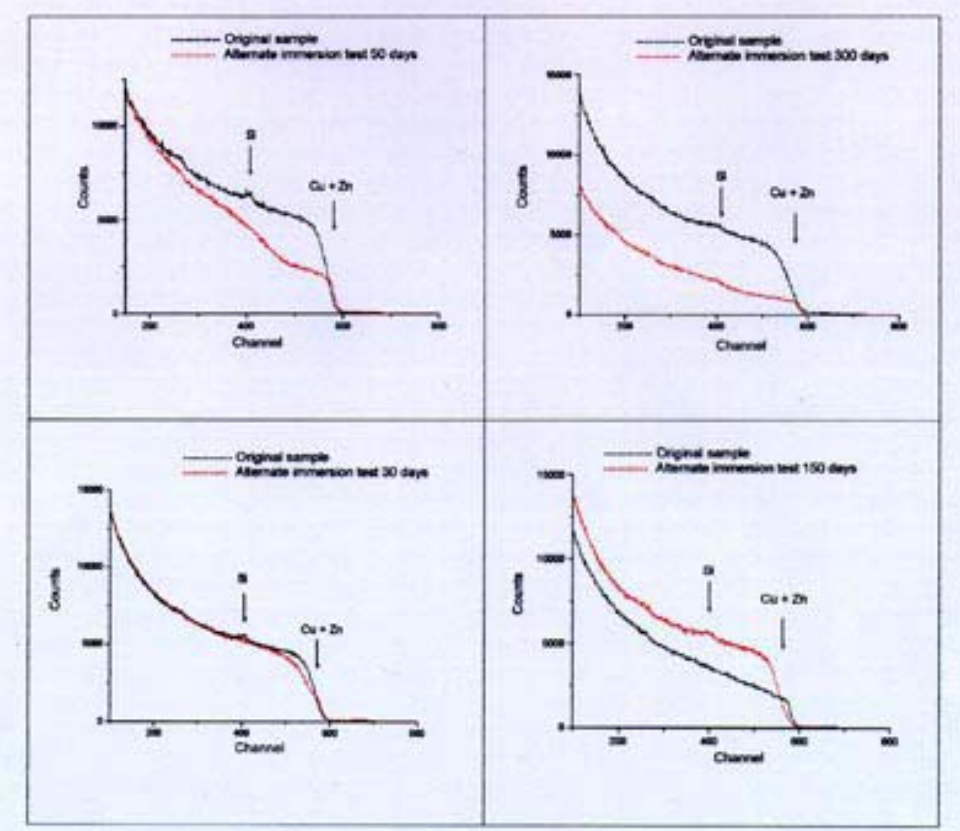

FIGURA 9 (a, b, c e d) - Gráficos apresentando os resultados de análise por RBS para as amostras de latão coletadas, respectivamente, com 30, 90, 150 [6] e 300 dias de ensaio acelerado. Desenho: Laboratório Van de Graaff do Departamento de Fisica da Pontificia Universidade Católica do Rio de Janeiro (PUC-RJ).

O resultado da medição da espessura da camada de produtos de oxidação na amostra final utilizando SEM foi da ordem de $4,4 \mu \mathrm{m}$. Esse valor não pode ser considerado exato, pois parte da camada pode ter se desprendido no processo de embutimento. No entanto, é um resultado bastante compatível com aqueles obtidos por RBS, já que a espessura da camada evoluiu de 0,05 para 0,8 $\mu \mathrm{m}$, num intervalo de 60 dias de ensaio, e daí para 4,4 $\mu$ m com mais 210 dias.

\subsubsection{Ensaio de exposição atmosférica}

As análises por DRX de todas as amostras produzidas no ensaio apresentaram sempre o mesmo resultado, identificando-se apenas a fase principal da liga $\mathrm{Cu}$ - Zn. A ausência na identificação de compostos adicionais tem relação, provavelmente, com a pequena quantidade dos mesmos na superfície da placa. Ao final dos ensaios, detectou-se também um composto relacionado à presença de poeiras na superfície. 
Macroscopicamente, as amostras tornaram-se opacas a partir do décimo dia de ensaio, e não haviam sido cobertas por camada contínua de produtos de oxidação até o final do período de estudo. Observou-se a formação de manchas marrom escuras, em algumas áreas, após 60 dias de ensaio.

O processo ocorreu muito lentamente e nos primeiros 10 dias não foi verificada qualquer alteração da superfície pelas técnicas instrumentais utilizadas. Aos 30 dias de teste, observou-se o aparecimento de áreas com produtos de oxidação, porém bem pequenas, com dimensões ao redor dos $3 \mu \mathrm{m}$, denotando estágios iniciais do processo de corrosão. A análise por SEM (EDS) em uma área com presença de produto de corrosão identificou a presença dos elementos de liga ( $\mathrm{Cu}$ e $\mathrm{Zn}$ ) e do oxigênio, sugerindo a presença de um óxido desses metais nesse local.

Aos 60 dias de ensaio, observou-se por SEM (aumento de 400x), a ampliação das áreas de corrosão na superfície em relação às amostras anteriores. Essas áreas apresentavam formato arredondado e dimensão média de $12 \mu \mathrm{m}$. A superfície da amostra encontrava-se bastante coberta de partículas de poeira. Esta presença, como já descrito no início desse trabalho, pode ser determinante para os processos de corrosão, como novamente caracterizado aqui. A análise por SEM (EDS), em área onde é observada a presença de produtos de oxidação, permitiu a identificação dos elementos de liga ( $\mathrm{Cu}$ e $\mathrm{Zn}$ ), além do oxigênio e do enxofre. A presença de enxofre não havia sido identificada anteriormente, indicando uma possível evolução na formação dos produtos de oxidação, em comportamento já constatado anteriormente (POURBAIX, 1973). Aos 90 dias de ensaio, observou-se por SEM, que partes da superfície encontravam-se cobertas por produtos de oxidação, mas sem formar uma camada contínua que a cobrisse. A Figura 10 apresenta imagens da superfície obtidas por SEM, pelas técnicas de (BSD), à esquerda, e (SEI), à direita, com ampliação de 400x.

Avaliando a mesma superfície em aumento superior (4.000x), como se observa na Figura 11, verifica-se que nessa área a superfície está coberta por um filme de produtos de oxidação. Na imagem à esquerda (BSD) verifica-se, pela presença de tonalidade diferenciada, a existência de produtos de pesos moleculares diferentes. 


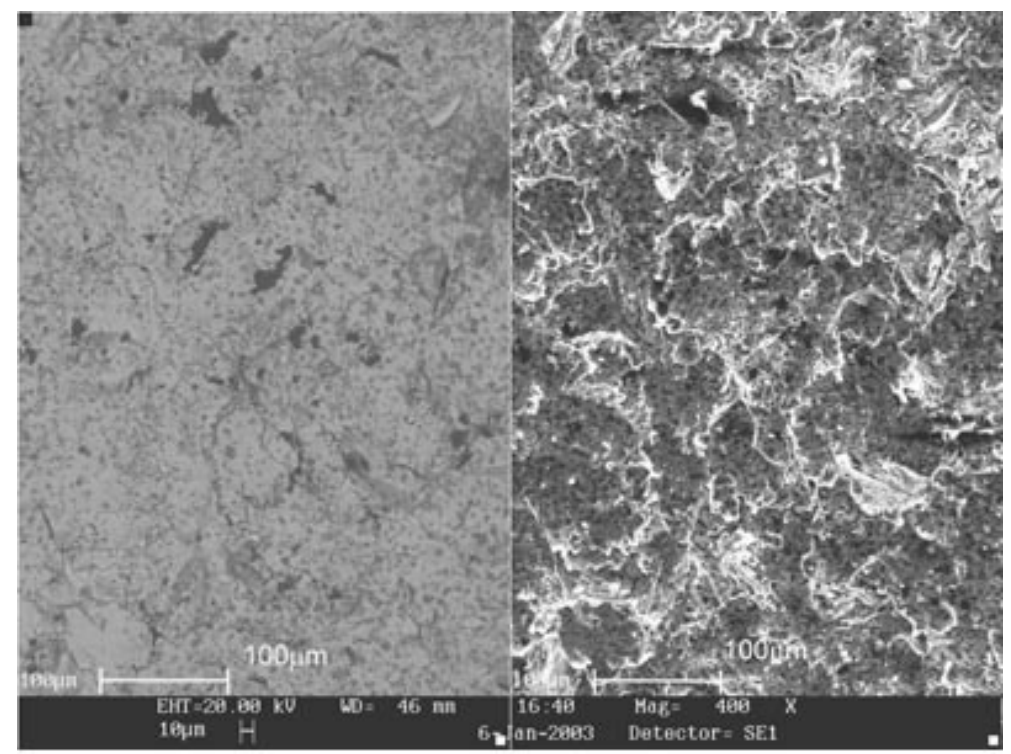

FIGURA 10 - Imagens obtidas por SEM, em aumento de $400 x$, pelas técnicas de BSD, à esquerda, e de SEI, à direita, mostrando a superfície da placa de latão após 90 dias de ensaio de exposição ao ambiente. Fotografias: Coordenação de Análises Minerais do Centro de Tecnologia Mineral.

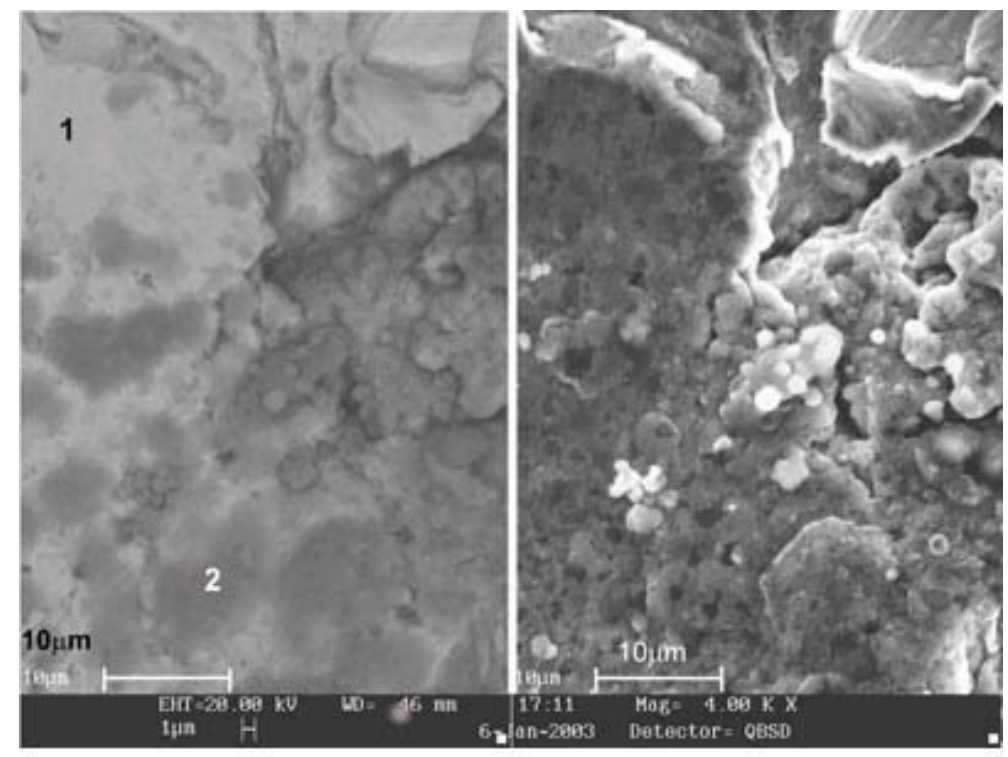

FIGURA 11 - Imagens obtidas por SEM, em aumento de $4000 \mathrm{x}$, pelas técnicas de BSD (composição), à esquerda, e de SEl (morfologia), aे direita, mostrando um detalhe da superficie da placa de latão após 90 dias de ensaio de exposição ao ambiente. Fotografias: Coordenação de Análises Minerais do Centro de Tecnologia Mineral.

A morfologia dos produtos de oxidação, mostrada na imagem à direita (SEI), caracteriza-se por uma forma grumosa. A tonalidade mais clara nas áreas mais externas onde o crescimento parece maior e apresenta formatos arredondados, tem relação com a concentração de elétrons nas áreas mais protuberantes (poder das pontas), gerando uma imagem que não tem relação, nesse caso, com a coloração da formação. 
A análise por SEM (EDS) foi realizada em dois pontos diferentes da mesma superfície com filmes de produtos de oxidação, sendo em uma área mais clara (ponto 1 na Figura 11) e em outra mais escura (ponto 2 na Figura 11). Na área mais clara, verifica-se a presença dos metais (Cu e $\mathrm{Zn}$ ) e de oxigênio, enquanto na mais escura encontra-se, além desses elementos, o enxofre.

Não se observou aqui, até o momento, o tipo de morfologia de crescimento de produtos de oxidação identificado no teste de imersão-emersão, com crescimentos de formato mais longitudinal, por estar, talvez, num estágio bem anterior àquele no qual esse comportamento foi observado no teste acelerado.

Os resultados obtidos por SEM, aos 150 dias de ensaio, ainda mostram a mesma característica de crescimento aqui caracterizada. As áreas com presença de produtos de oxidação apresentam forma arredondada e tamanhos bem superiores aos verificados anteriormente, com manchas de 300 a $400 \mu m$ de maior dimensão. As análises realizadas com a técnica EDS apresentaram resultados similares aos obtidos com 90 dias de ensaio.

A Figura 12 mostra imagem de SEM (BSD-composição), com ampliação de 50x, após 300 dias de ensaio de exposição atmosférica. Aparentemente, essa área da superfície encontra-se completamente coberta por filmes de produtos de oxidação, além de ser perceptível a existência de compostos de pesos moleculares diferentes. Os filmes superficiais existentes, no entanto, apresentam espessura muito menor do que aquelas verificadas no teste acelerado (imersão-emersão).

Novamente, a superfície da amostra mostrou-se muito empoeirada e os resultados da análise elementar por EDS foram similares aos anteriormente apresentados. A Figura 13 apresenta, com ampliação de 400x, imagens obtidas pelas técnicas de (BSD), à esquerda, e (SEI), à direita.

Observa-se, na imagem à direita, a presença das partículas de poeira e à esquerda, a imagem dessa mesma área mostrando a presença de região com produtos de oxidação da liga de base. Comparando-se a imagem apresentada à direita nessa figura com aquela mostrada, também do lado direito, na Figura 3 (estado inicial da 
superfície), verifica-se que a morfologia alterou-se nesse período, devido à formação dos filmes de produtos de oxidação.

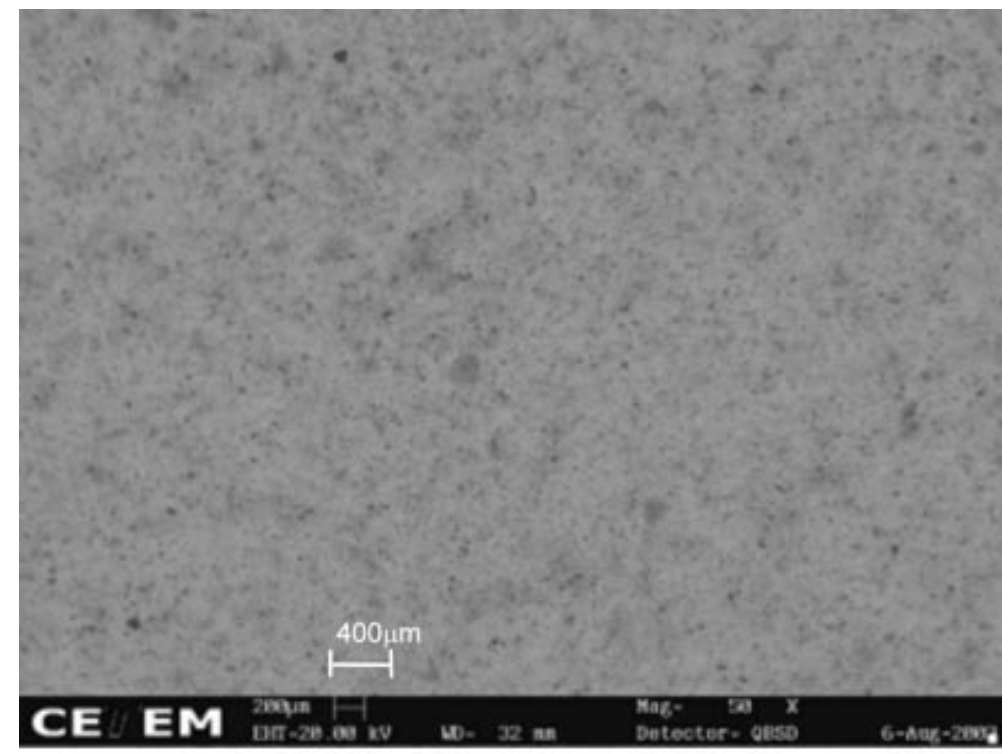

FIGURA 12 - Imagem obtida por SEM (BSD), com aumento de 50x, mostrando a superficie da placa de latão após 300 dias de ensaio de exposição atmosférica. Fotografias: Coordenação de Análises Minerais do Centro de Tecnologia Mineral.

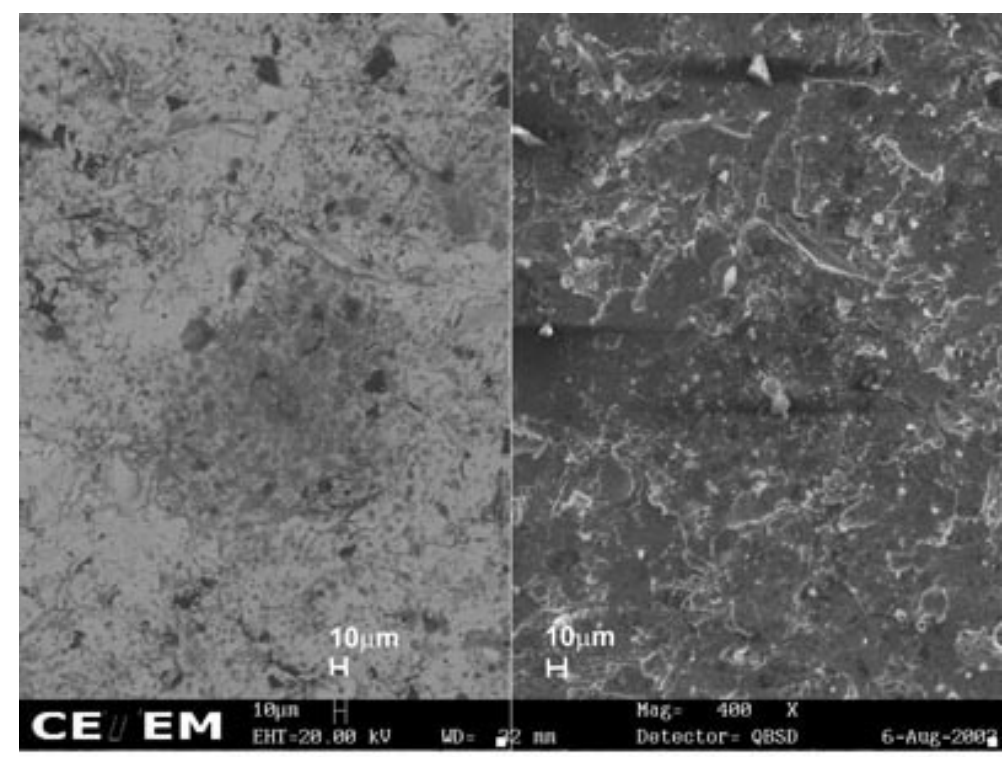

FIGURA 13 - Imagens obtidas por SEM, em aumento de $400 x$, pelas técnicas de BSD, à esquerda, e de SEI, à direita, mostrando o aspecto da superficie da placa de latão após 300 dias de ensaio de exposição ao ambiente. Fotografias: Coordenação de Análises Minerais do Centro de Tecrologia Mineral.

Os resultados obtidos pela análise por RBS estão apresentados na Figura 14. Os elementos constituintes da liga ( $\mathrm{Cu}$ e $\mathrm{Zn}$ ) foram identificados e o silício detectado relaciona-se aos resquícios de material utilizado para o preparo da superfície. Verifica-se que todas as curvas estão superpostas, menos aquela referente aos 300 dias de ensaio. Portanto, nenhuma alteração na superfície das amostras foi 
detectada até os 150 dias de ensaio. Aos 300 dias detectou-se a formação de uma camada contínua de produto de oxidação, cuja espessura pode ser estimada em $0,05 \mu \mathrm{m}$.

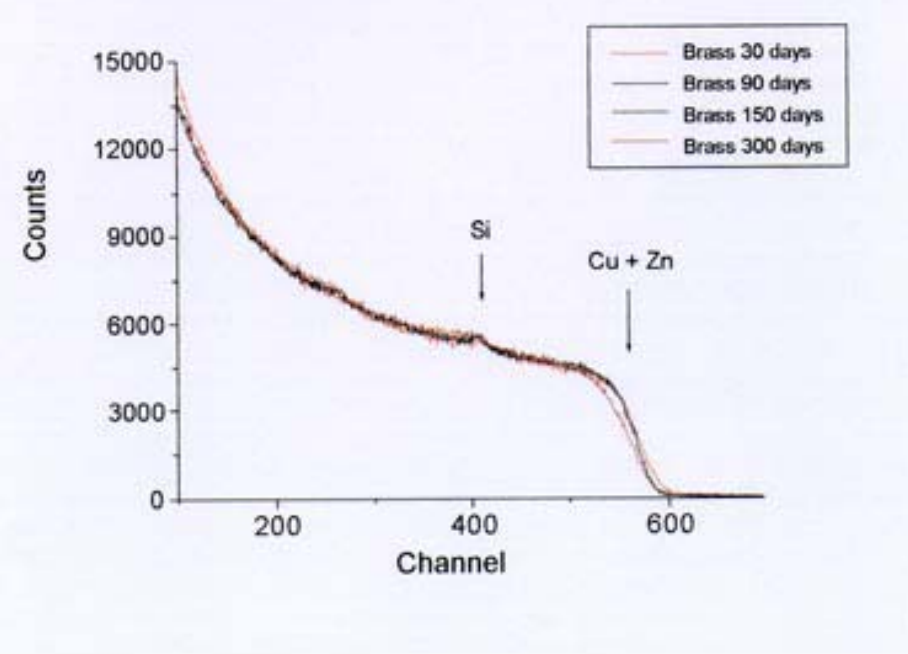

FIGURA 14 - Gráficos apresentando os resultados das análises por RBS para as amostras de latāo no ensaio de exposição atmosférica. Desenho: Laboratório Van de Graaff do Departamento de Fisica da Pontificia Universidade Católica do Rio de Janeiro (PUC-RJ).

Com a amostra final não foi possível obter qualquer resultado de medição de espessura da camada de depósitos por SEM, pois a camada não foi preservada, talvez por ser muito fina e ainda não muito aderente.

\subsubsection{Comparação entre os diferentes ensaios}

Os estudos aqui realizados com latão, em ambiente fechado típico de museu de clima tropical, mostram que os processos são realmente muito lentos, confirmando outros estudos para cobre (RICE et al, 1980; SCHUBERT; D'EGIDIO, 1990). Esses processos, no entanto, não foram tão lentos que não permitissem a formação de pátinas na superfície das amostras. Nos testes acelerados, formou-se uma pátina de coloração verde muito escura, em 150 dias. Portanto, apesar do processo ser lento, é relativamente mais rápido do que o que foi observado nos estudos já citados, em função da umidade relativa na área onde se desenvolveram os estudos desse trabalho estar em valores bem superiores. 
Em ambos os testes realizados, o primeiro composto formado no processo de oxidação da liga estudada foi identificado, por análise de DRX, como a cuprita $\left(\mathrm{Cu}_{2} \mathrm{O}\right)$. A análise elementar por SEM (EDS) confirma a formação inicial de compostos contendo os metais e oxigênio e, por outro lado, por essa última técnica também foi detectada a formação posterior de compostos contendo os metais, o oxigênio e o enxofre, numa possível evolução do processo similar à postulada para o cobre por Pourbaix (1973).

Ao final dos estudos, o aspecto das superfícies das amostras de latão, nos ensaios de exposição atmosférica, mostrou-se em um estágio comparável ao observado entre os 10 e os 30 dias de ensaio acelerado. Procurou-se fazer, a partir dos resultados obtidos por RBS, uma correlação entre os dois tipos de ensaios através da determinação da espessura da camada de produtos de oxidação formada na superfície das amostras.

A espessura de camada medida para o teste de imersão-emersão, referente a 30 dias de ensaio, foi equivalente àquela obtida por exposição atmosférica com 300 dias de teste. Portanto, o fator de multiplicação entre as escalas de tempo desses ensaios pode ser em torno de 10. Assim, espera-se que a mesma espessura de camada obtida no teste acelerado com 90 dias seja obtida após cerca de 900 dias de exposição ao ambiente estudado. Os resultados encontrados para 300 dias de teste de imersão-emersão seriam, assim, equivalentes à exposição ao ambiente por cerca de oito anos.

Os resultados obtidos nesse estudo permitem afirmar que foi possível simular de forma acelerada, em linhas gerais, o processo de corrosão em ambiente fechado. Por outro lado, essa simulação não se dá de forma perfeita. Mesmo não utilizando a lâmpada artificial da unidade, que simularia a luz solar, não existente no ambiente fechado, a imersão das amostras em água por determinados períodos introduz alguns fenômenos físicos e químicos que podem não ocorrer em ambientes fechados, já que não existe a possibilidade de molhamento da superfície das amostras. 
A presença de partículas de poeira, determinante para o início do processo corrosivo, pode ser comprometida pelo estágio de imersão das amostras. Por outro lado, foram identificadas partículas de poeira na superfície das amostras do teste acelerado, mostrando que o comprometimento desse fator não é completo. Pelos estudos foi possível verificar que a forma de crescimento das camadas de produtos de oxidação foi diferente nos testes acelerado e de exposição ao ambiente. No teste acelerado verificou-se um ataque preferencial ao que parecem ser os contornos de grão da estrutura e já no teste de exposição ao ambiente o ataque foi generalizado, provavelmente fruto da presença de partículas de poeira em toda a superfície, sendo esses os locais preferenciais de início de processo de corrosão.

É importante assinalar que a simulação com ensaios de imersão-emersão para ambientes externos lida com eletrólitos passíveis de serem conhecidos. Já no ambiente interno, o eletrólito é desconhecido e sabe-se de sua existência apenas pela constatação da ocorrência de processos corrosivos nos objetos ali presentes.

Não foi escopo desse trabalho determinar as velocidades dos processos de corrosão envolvidos por métodos tradicionais, como a perda de peso e/ou espessura, o que poderá ser realizado no futuro, permitindo então uma melhor comparação com dados obtidos na bibliografia para ambientes externos. Será interessante também continuar os testes de exposição atmosférica, como previsto, pelo prazo de cinco anos, de forma a acompanhar o processo real de formação das camadas de produtos de oxidação.

\section{Conclusões}

Foi possível simular, em linhas gerais, de forma acelerada o processo real de corrosão atmosférica em ambientes internos, através de testes de imersão-emersão adaptados. No entanto, as formas de crescimento das camadas de produtos de oxidação foram diferentes, com prevalência do efeito da presença de partículas de poeira sobre a superfície no teste de exposição ao ambiente e do efeito dos contornos de grão da estrutura da liga no teste acelerado.

O processo de corrosão para o latão em ambiente interno típico de museu situado em clima tropical foi muito lento e a presença de partículas de poeira foi 
determinante para o início dos processos de oxidação. O primeiro produto de oxidação formado na superfície das amostras foi a cuprita, identificada por DRX. Não foi possível identificar compostos contendo enxofre, porém as análises por SEM (EDS) mostraram a presença desse elemento na superfície das placas, a partir de determinado período de ensaio.

Foi possível sugerir uma relação entre as escalas de tempo dos testes de imersãoemersão e de exposição atmosférica, resultando que cada 30 dias de ensaio acelerado corresponderam a cerca de 300 dias de exposição ao ambiente estudado. Essa relação numérica permite apenas uma previsão a grosso modo do fenômeno em tempo real.

\section{Referências Bibliográficas}

GRANATO, Marcus; SANTOS, Leandro Rosa dos; MIRANDA, Luiz Roberto Martins de. Studies in the conservation of historic scientific instruments at the Museu de Astronomia e Ciências Afins (Brazil) - Preliminary results. In: CONGRESO LATINO AMERICANO DE RESTAURO DE METALES, 1, 2002, Santiago. Anais eletrônicos... Santiago, Chile, 19 a 23 jun. 2002.

GRANATO, Marcus. Restauração de instrumentos científicos históricos. 2003. Tese (Doutorado) - Programa de Pós-Graduação em Engenharia Metalúrgica, Coppe/UFRJ, Rio de Janeiro, 2003.

HATCHFIELD, Pamela. Pollutants in the museum environment. London: Archetype Pub., 2002.

LAGO, Dalva Cristina Batista do. Estudo da formação de produtos de corrosão em monumentos de bronze da cidade do Rio de Janeiro: aplicação de pátinas artificiais em restauração. 2001. Tese (Doutorado) - Programa de Pós-Graduação em Engenharia Metalúrgica, Coppe/UFRJ, Rio de Janeiro, 2001.

MINIATI, M.; BRENNI, P. Restauro di strumenti storico-scientifici e filosofie di intervento. In: BITELLI, M. (Ed.). Restauro di strumenti i materialli: scienza, musica, etnografia. Florença: Nardini Editore, 1993. p.51-57.

NAZAROFF, William et al. Airborne particles in Museums. Los Angeles: Getty Conservation Institute, 1993.

POURBAIX, Michel. Lectures on electrochemical corrosion. Nova lorque: Plenum Press, 1973.

POURBAIX, Michel. Lições em corrosão eletroquímica. Bruxelas: Cebelcor, 1987.

RICE, David et al. Indoor corrosion of metals. Atmospheric Corrosion, [s.I.], v.4, n. 27, p.891- 901, 1980. 
SCHUBERT, R.; D'EGIDIO, S. M. The surface composition of copper with indoor exposures ranging from 3 to 49 years. Corrosion Science, [s.I.], v.30, n.10, p.999-1.008, 1990.

STAMBOLOV, Todor. The corrosion and conservation of metallic antiquities and works of art. Amsterdam: CL Publication, 1985.

VANDER VOORT, George F. Metallography, principles and practice. Nova lorque: McGraw-Hill, 1984.

*Engenheiro metalúrgico. Doutor em Engenharia Metalúrgica - Coppe/UFRJ. Museu de Astronomia e Ciências Afins - MAST/MCT.

**Engenheiro químico. Doutorando do Programa de Pós-graduação em Engenharia Metalúrgica da Coppe/UFRJ.

${ }^{* * *}$ Engenheiro metalúrgico. Doutor pela Universite Libre de Bruxelles. Professor associado da Coppe/UFRJ.

O desenvolvimento desse trabalho teve apoio do Conselho Nacional de Desenvolvimento Científico e Tecnológico (CNPq). 